\title{
Measuring the Thermal Comfort and the Sound Level in Design Studio Classes in Architecture Engineering Colleges
}

\author{
Dr. Hind Abdelmoneim Khogali ${ }^{1,2}$, Students Mohammad Altuwijr ${ }^{1}$, Wadhah Alshaikh ${ }^{1}$, Ibrahim ${ }^{1}$, \\ Almohaimeed-saleha Alrasheed ${ }^{1}$, Meznah Aloyuni ${ }^{1} \&$ Alhanouf Almutiri $^{1}$ \\ ${ }^{1}$ College of Architecture Engineering and Digital Design, Dar Al Uloom University, Saudi Arabia \\ ${ }^{2}$ Prince Sultan University, Saudi Arabia \\ Correspondence: Dr. Hind Abdelmoneim Khogali, College of Architecture Engineering and Digital Design, Dar \\ Al Uloom University, Architecture Department, Saudi Arabia. E-mail: ahind@dau.edu.sa
}

Received: April 7, 2020

doi:10.5539/jsd.v13n4p35
Accepted: May 14, $2020 \quad$ Online Published: July 17, 2020

URL: https://doi.org/10.5539/jsd.v13n4p35

\begin{abstract}
Thermal comfort is one of the most important topics in the course Environmental Control, ARC404 assign to Architecture program in the college of architecture Engineering and Digital Design, 6 students in this course will share in the research, will distribute in three groups. This research is aiming to let the students learn and practice how to measure the thermal comfort in-studio classes focusing on the temperature, the humidity, and the noise, analysing and find solutions. The methodology of the research is based on using monitor devices; noise level smart meter, smart temperature and humidity measurement meter with data analysis by using Excel computer program as well as, distrusting a survey to know the user's opinion. The college has three types of a studio class, one facing the courtyard, with large glass window, the second at the middle of the corridor with high-level window, the third one is far away from the courtyard without any window. The results compared by The United Nation Environut Protection Agency (EPA) noise levels. The results show that the studio class CBC09 level of sound exceed $60 \mathrm{~dB}$ which consider as noise. Also, the class $\mathrm{CBC} 01$ is the most comfortable class because of 25 $\mathrm{C}^{\circ}$ temperature, $40 \%$ humidity and $55 \mathrm{DB}$ the sound level is also exceed the limit by EPA. The conclusion of the research paper will highlight some scientific solutions in walls, ceiling and floors for the studio classes to be applied in the future.
\end{abstract}

Keywords: measuring thermal comfort, temperature control, humidity control, sound level control in studio classes, scientific solutions

\section{Introduction}

The design studio halls in Architecture department are suffering from noise because the main walls are made from glass plywood partitions, this cause problem of discomfort for the students and teachers during the lecture because of sound transfer... Also, because of the glasses are in the basement this cause high humidity in winter and high temperature in summer.

Although measuring the thermal comfort in design studio classes became significance in measuring the sound and noise level, temperature and humidity in the class and find out scientific solutions. its significant for the studio classes in DAU will provide more comfortable places for the students, and for the community, it will attract more students if we improve the situation in the internal environment.

\subsection{Objectives of the Research}

1) To measure the thermal comfort in the design studio classes in Architecture Department.

2) To let the student share in scientific research in course Environmental control.

3) To encourage the students using the monitoring system such as, sound smart meter and temperature smart thermometer

4) To encourage the students working in groups.

5) To learn the students the main steps of doing scientific research.

6) The research will be discussed in Prince Sultan Forum for students researches and this will let DAU students 
having the experience to share in conferences, discussing their results and have experience in presentation, and meet with the professionals.

7) To use the main instruments used in the research for other faculty members for other researches in the future and will establish scientific Lab for female students and faculty members.

\section{a. Research Problem}

The main research question: Do the design studio classes comfortable for students and teachers?

To answer this question, the research will monitor the thermal comfort in-studio classes in the college of architecture engineering and digital design, the researchers choose three classes in each side male/female

\section{$\mathrm{CBC} 01 / \mathrm{ABC} 01, \mathrm{CBC} 07 / \mathrm{ABC} 07$ and $\mathrm{CBC} 09 / \mathrm{ABC} 09$.}

Because they have different designs, especially in window size, the amount of natural lighting

\section{Literature Review}

Abdelmoneim, H. (2020) discussed in the paper Benchmarking case study different global systems compare with the local system SEBAM, one of the major sustainable eco buildings principles is studying the indoor environmental quality focusing on the natural ventilation. Abdelmoneim, H. (2020) discussed the Greater Khartoum local system Assessment Method to Evaluate sustainable- eco -buildings (SBAM) the system discussed the indoor environmental quality in using the ecological building material, natural ventilation, sustainable lighting.

Laaeddine, R., Wu, S. \& Del, E. (2019) discussed in their paper the Occupancy, windows, opening and, closing, shading control, equipment use, lighting control, Thermostat adjustment and give the Advantages and Disadvantages. Mahmoud, S.(2019) discussed in her paper different sources of noise such as image noise, speakers noise and mechanical system noise which are affect human health. Abdelmoneim, H., (2019) discussed the six basic factors of thermal confort which are the humidity, the temperature, radiant temperature, air velocity, metabolic heat, and human clothing this research is focusing on the humidity and temperature and the noise. Alserf, M., (2019) stated in his book 'Sustainable Houses in Saudi Arabia', human health and well being are one important principle of LEED.

ASHRAE(2019) discussed Standard 62.1-2019 and stated Humidity control requirements are now expressed as dew point and not as relative humidity.

The united State Environmental Protection Agency EPA (2017) discussed the monitoring system that used in schools and universities and stated to set the cschool bus and other vehicles inside the school in particular space for airborne and noise. In addition the added establish and implement a regular schedule for maintaining unit ventilators, replacing air filters, cleaning supply air diffusers, return registers and outside air intakes and commission the HVAC system a minimum of once every 5 years.

Hassan, S., (2007) stated in his book 'Lighting and Acoustics in Architecture' most of the problems in the modern design with open spaces are because of using lightweight structure without acoustical privacy especially in open lecture halls and open spaces which cause spread of the noise between these lecture halls.

Jalil, A., Mjid, M. and Safa, Kh. (2012) published a paper about measuring the noise levels in college of architecture engineering, civil epartment and stated that the sound level in the whole building reach 76.7 which exceed the limit of acepted sound level at universities.the EPA is recommended the sound level between 40-30 for universities.

(KAUST, 2013) stated in the report that energy-saving can be achieved by studying windows, solar screening, glazing and building insulations. Hassan, S., (2002) stated in his book the heat transfer in buildings through walls, heat exchange between the human and the surroundings, the internal thermal comfort can be controlled by using the natural ventilation through the windows or by using the mechanical means. Mcmullan, R.(2002) discussed the importance of natural ventilation in classes between 3-4 air changes per hour and added the moisture inside the buildings caused by human activities like breathing and cooking. (Schiavon, S., 2010) Personalized ventilation (PV) is an individually controlled air distribution system aimed at improving the quality of inhaled air and the thermal comfort of each occupant the study reach to the PV may reduce the energy consumption up to $51 \%$ following the natural ventilation. Wazeri, Y., (2010) concluded that the use of interior courtyards has been one of the useful solutions that have been adopted in ancient Nubian Architecture, especially evident in the Tushki village. The study proved that a square plan wind tower should not exceed a height of 6 metres in cases, wherein it is used for a building of 3 metres height. Moreover, the study revealed that the use of rectangular shape is better than the cubic shape; and its height does not exceed 1 metre over the water level, specifically when the 
water flow is 10 litres/min. (Araújo de, 2018) measured the thermal comfort in space by $2 \times 2$ in air temperature, relative humidity, wind speed, and solar radiation and computer by the research results. The surface/ volume ratio is very important in conserving heat transfer in and out of a building. To conserve heat or cold the building must be designed with a compact form in order to reduce the efficiency of the building as a heat exchanger. Specifically, buildings can have very different perimeters and area ratios depending on their plan form. For example, an important ration in eco-building is the Surface Volume Ratio (SVR), which refers to the ratio of the exterior surface to the enclosed volume of the building and it should necessarily be controlled. The main objective in calculating the SVR is to minimize the area of exposed surfaces in order to reduce heat gain. This can be achieved through multi-story buildings and by raising the roof height (Fajal, 2002).

Alwakil, Sh. (1989) discussed the building form as one of the important solutions of passive solutions, particularly for the Middle East, the researcher concurs that the building form could constitute a part of the indoor environment or a part of the environmental design process like other principles. Correspondingly, the factors of water, energy, material, and site present environmental, economic and social alignment, while, the outdoor environment shows environmental and social alignment.

Fanger, P.O., (1970) used heat balance equations and empirical studies in the context of skin temperature to define the comfort parameter, developed the Predicted Mean Vote index (PMV) model. The standard thermal comfort surveys ask subjects about their thermal sensation on a seven-point scale from cold $(-3)$ to hot $(+3)$. Correspondingly, Fanger's equations are used to calculate the Predicted Mean Vote (PMV) (Fanger, 1970). (Jaramillo, A. 2012) discussed the sound level in classes should not exceed $60 \mathrm{Db}$.

Noise levels in schools

- $\quad$ Noise level at proposed school façade $60 \mathrm{~dB}$

Minimum distances between educational buildings and transportation noise sources: It is considered best practice to locate schools $328 \mathrm{ft}(100 \mathrm{~m})$ from any busy road or railway line; however, it is anticipated that achieving these

that acoustics in the classroom can impact on student memory retention and concentration levels. The research shows that the acoustic environment can alter performance in mathematics, problem-solving, reading ability, language skills, and impact on literacy levels

Acoustic Panels

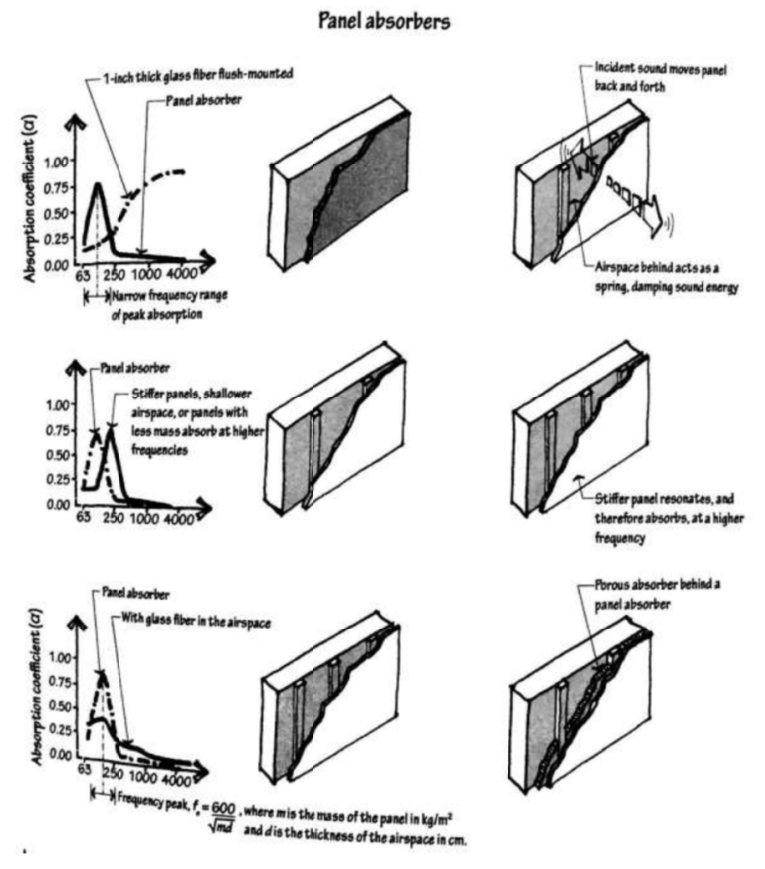

Figure 1. A good absorber, blow through it under moderate pressure. Absorption effectiveness is a function of thickness, fibre orientation, density, and porosity (Ermann, M. 2005), copyright @(Ermann, M. 2005) 


\section{Definition of the frequency}

- The Frequency is a study sound is produced by the repeated back and forth movement of an object at regular intervals. The time interval over which the motion recurs is called the period (Jaramillo, A. 2012)

$\mathrm{Or}$

- the rate at which something occurs over a particular period of time or in a given sample. (Long, M. 2014)

\section{The Methodology}

\subsection{Firstly: The Use of Sound Meter and the Thermometer}

The methodology of the research is based on using monitor devices; sound level smart meter, temperature and humidity measurement smart meter with data analysis by using Excel computer program. Its quantitative research based on monitoring by smart meter

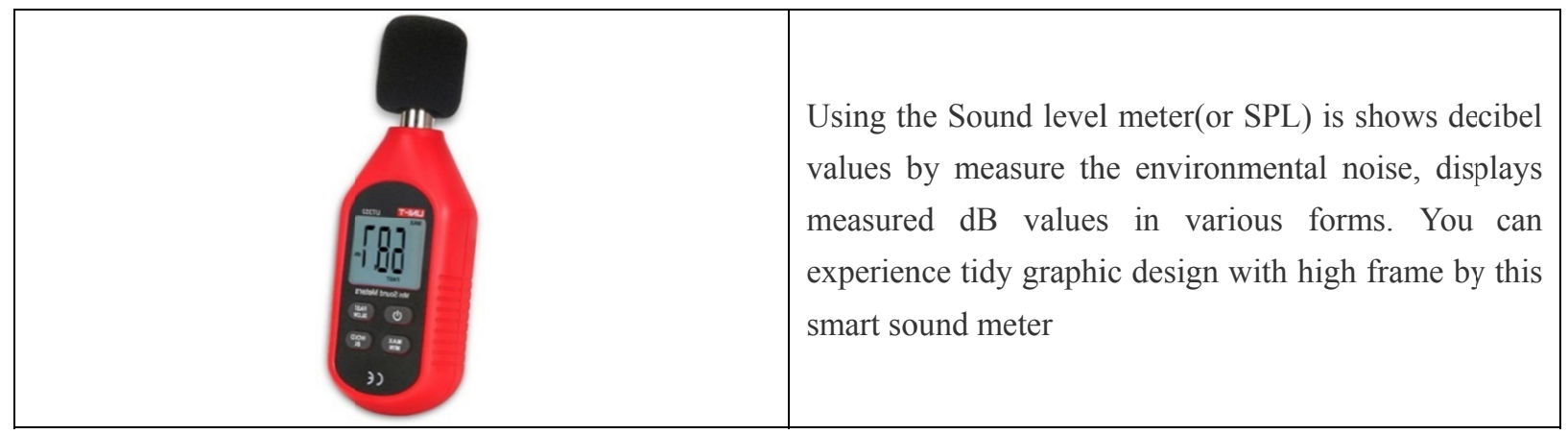

Figure 2. The sound level meter, used to measure the sound level in the studio class (SOUQ.com, 2020)

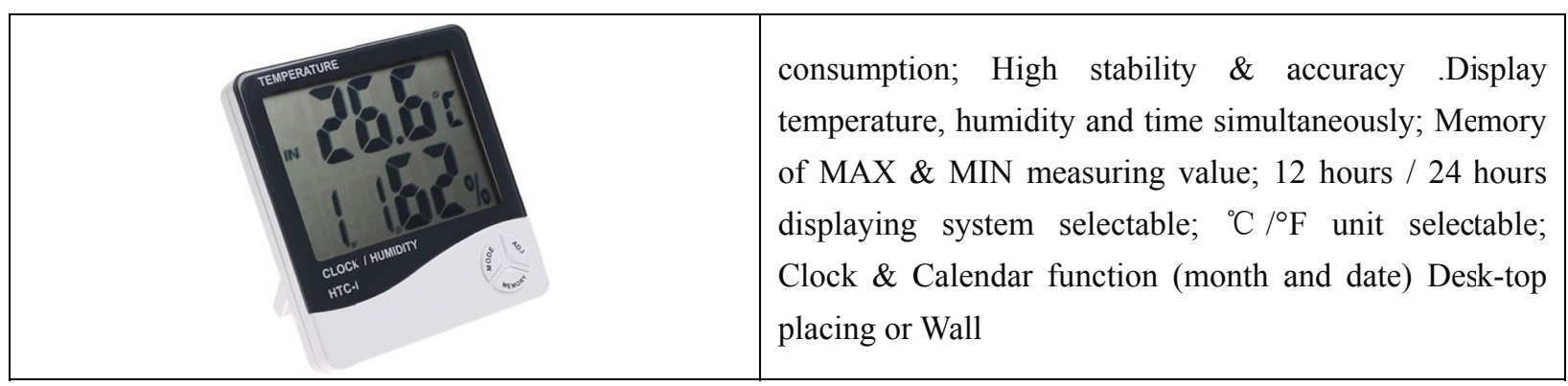

Figure 3. The thermometer used in measuring the temperature and Humidity in Studio class (SOUQ.COM, 2020)

\subsection{Secondly: Distribution Survey}

Distribution survey to the students in the studio classes to have their response to the temperature, humidity and sound level. 
The results of the survey

- A survey was distribute to the students in studio class

- Total number of students in studio classes 50 students

- All the total number of students in studio classes are Answer the questions
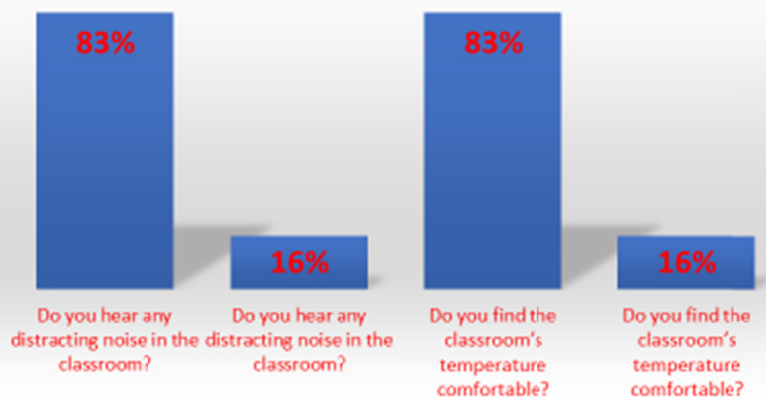

Figure 4 . The result of the survey: $83 \%$ they hear disturbance noise in the classes 


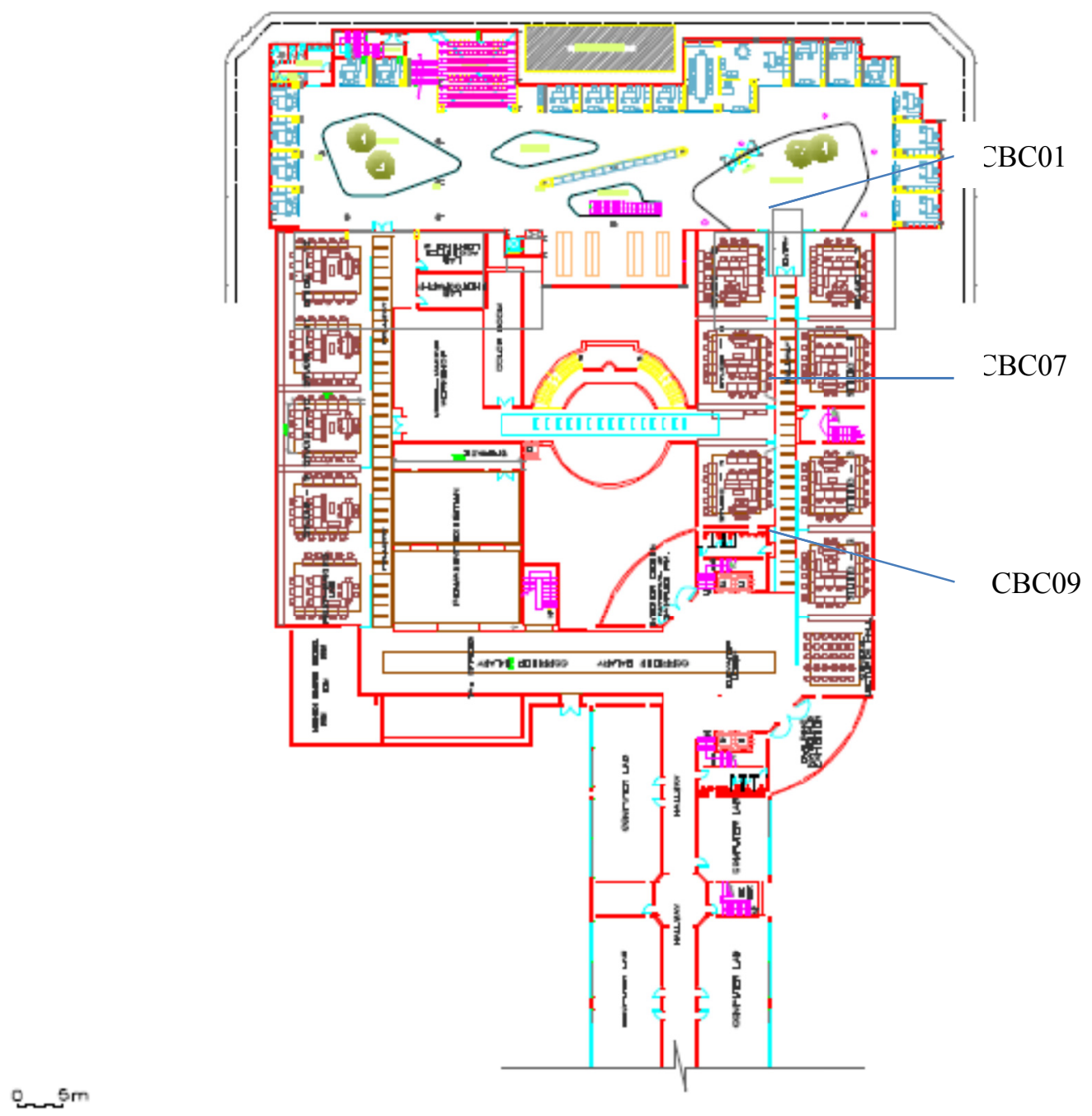

Figure 5. The location of the case study, Female section, Copyright@DAU 


\section{Findings}

\section{Internal and External Temperature CBCO1}

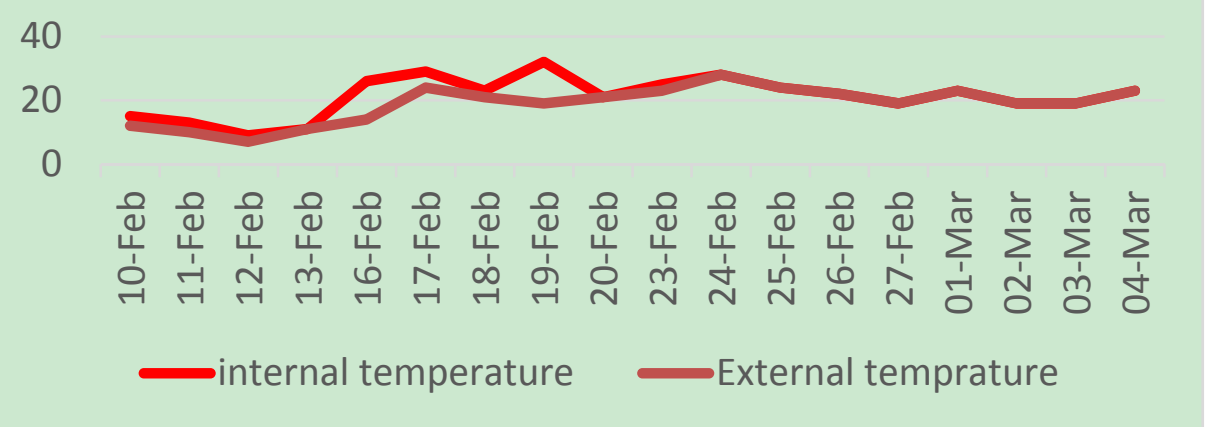

Figure 6. The average result of the internal $21 \mathrm{C}^{\circ}$, The Average result of the External $18 \mathrm{C}^{\circ}$

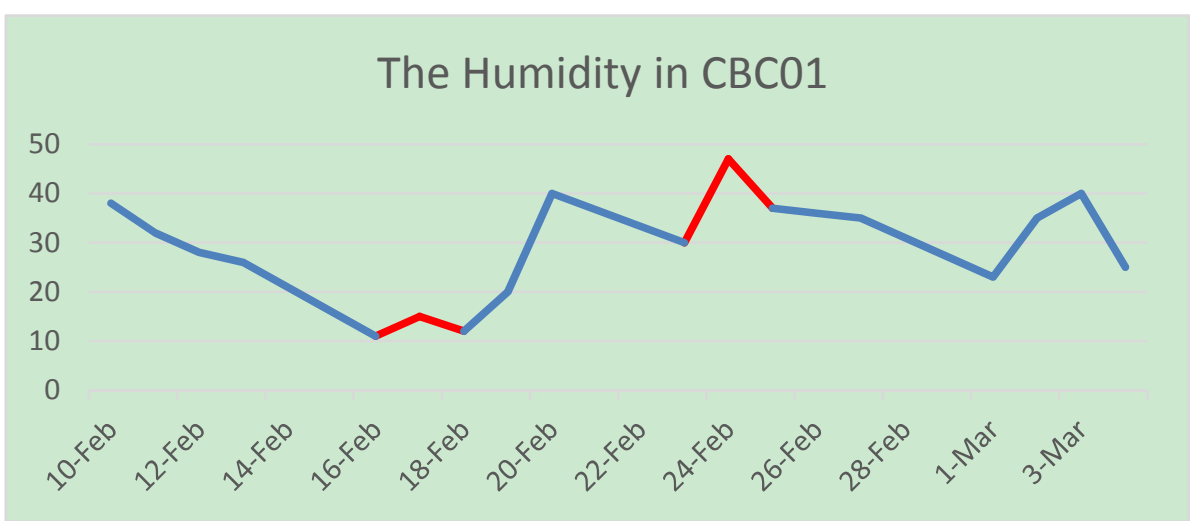

Figure 7. The Max Humidity $45 \%$, Min Humidity is $15 \%$

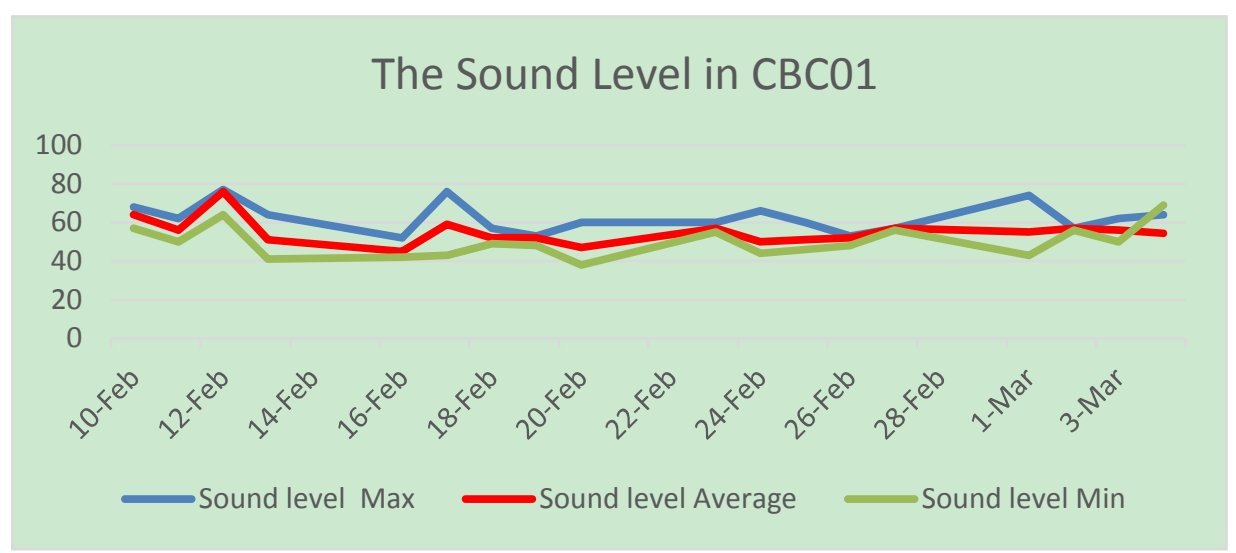

Figure 8. Max Sound Level $62 \mathrm{~dB}$, Average $55 \mathrm{~dB}$, Min $50 \mathrm{~dB}$ 


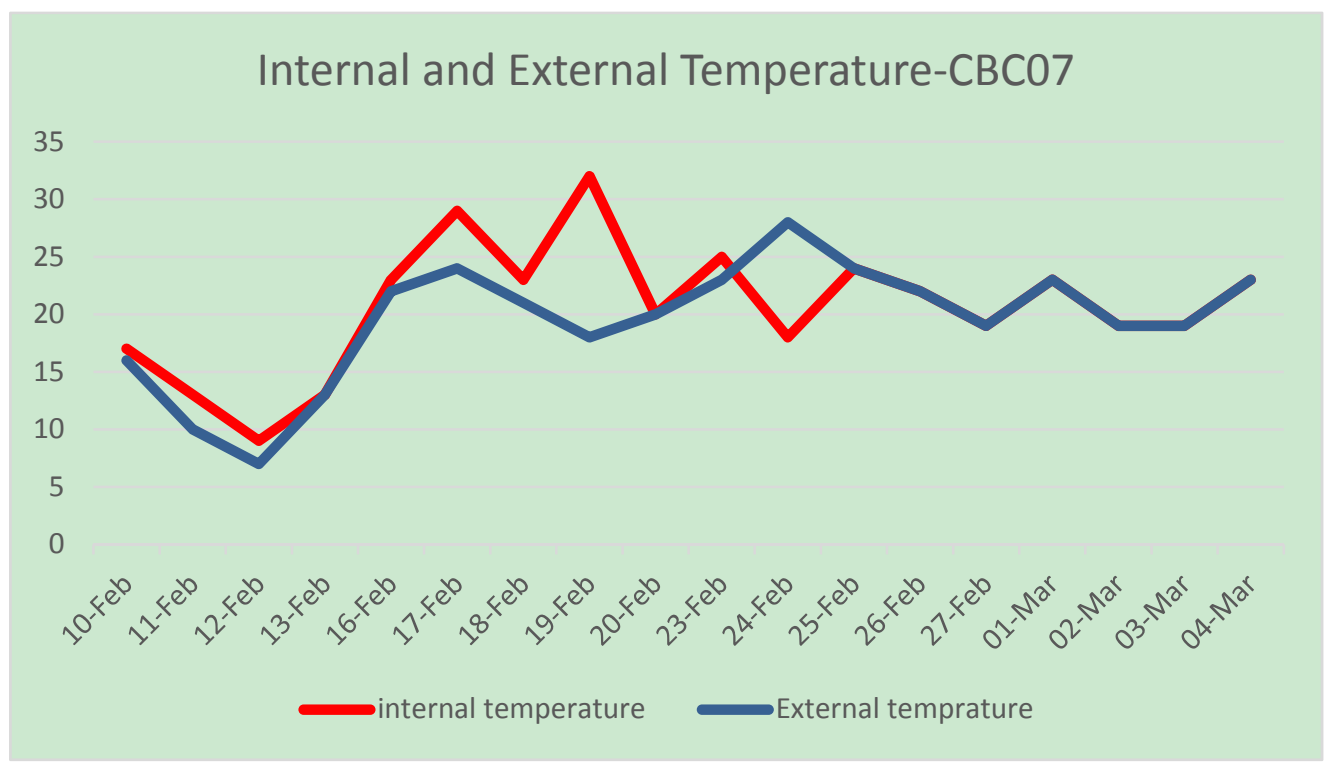

Figure 9. The average result of the internal $21 \mathrm{C}^{\circ}$, The Average result of the External $20 \mathrm{C}$

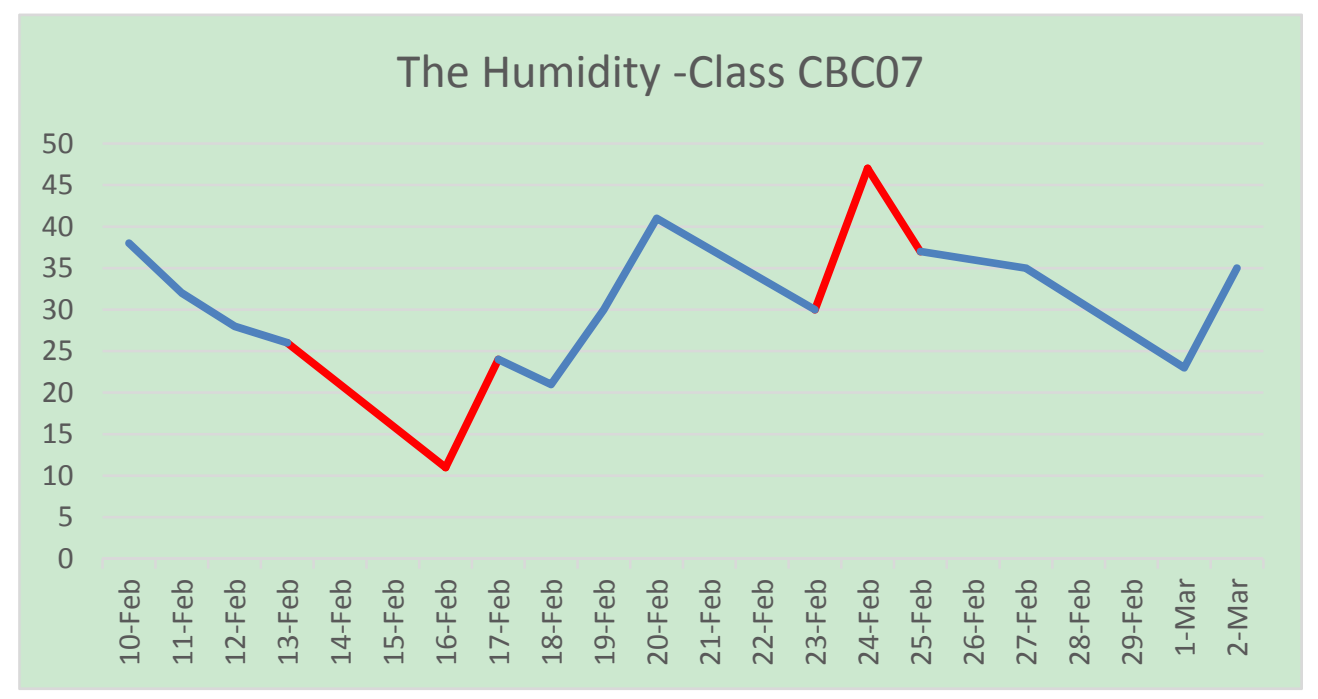

Figure 10. The Max Humidity $47 \%$, Min Humidity is $12 \%$

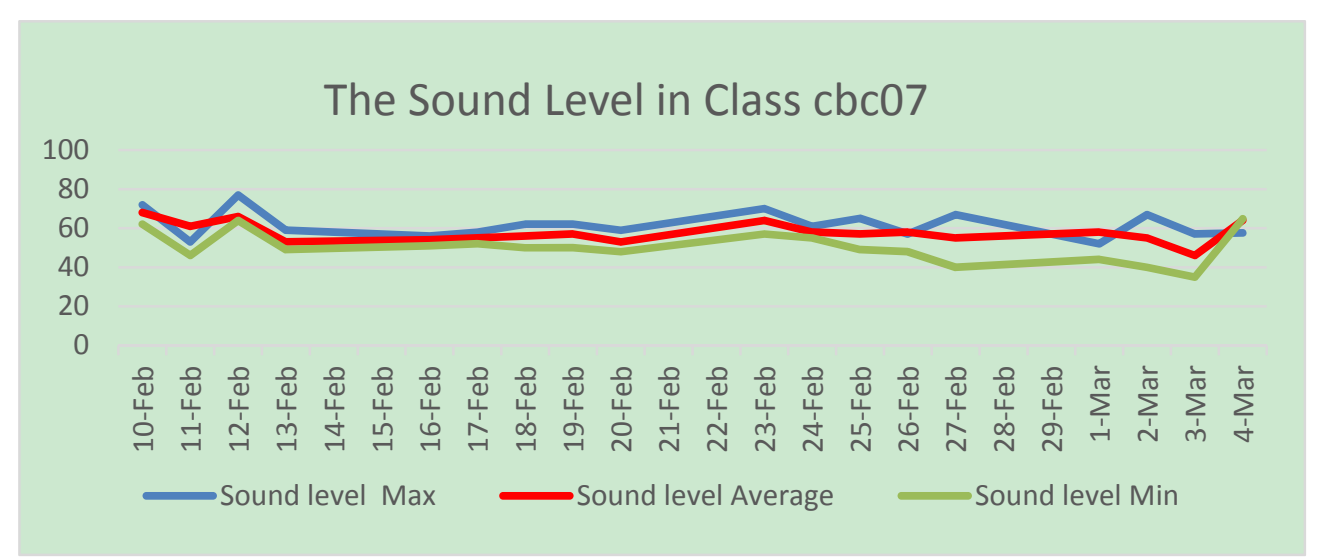

Figure 11. Max Sound Level, 62 Db. Average 58 dB, Min 50 dB 


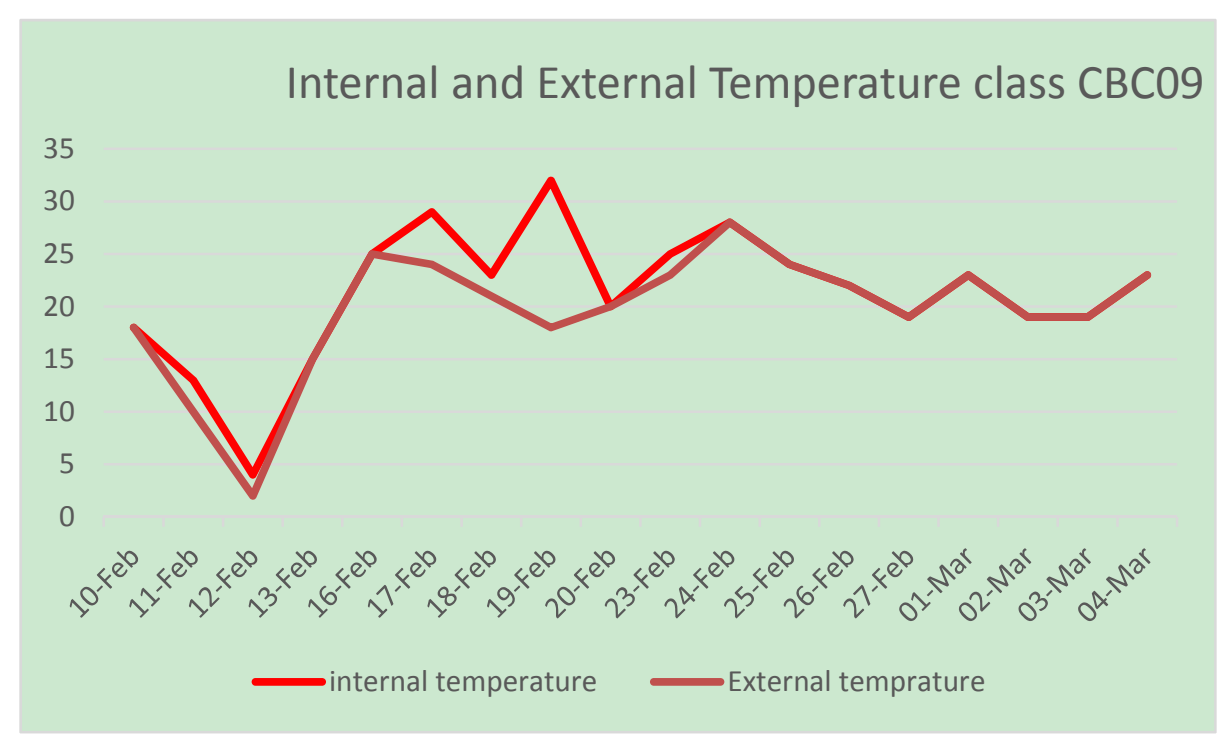

Figure 12. The average result of the internal $21 \mathrm{C}^{\circ}$, The Average result of the External $20 \mathrm{C}^{\circ}$

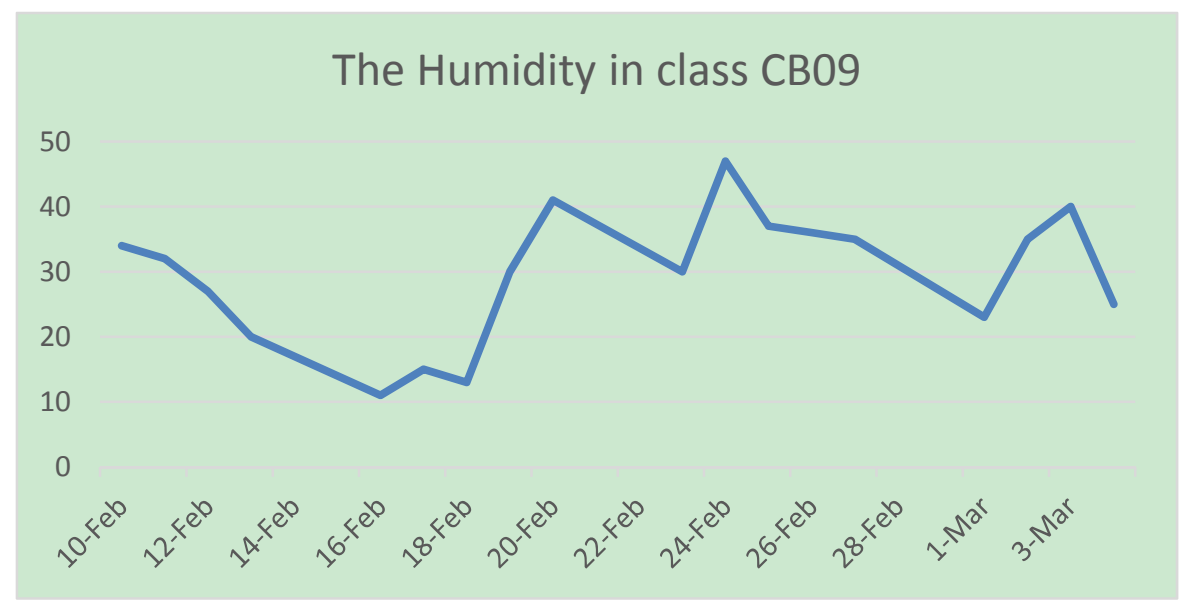

Figure 13 . The Max Humidity $47 \%$. Min Humidity is $12 \%$

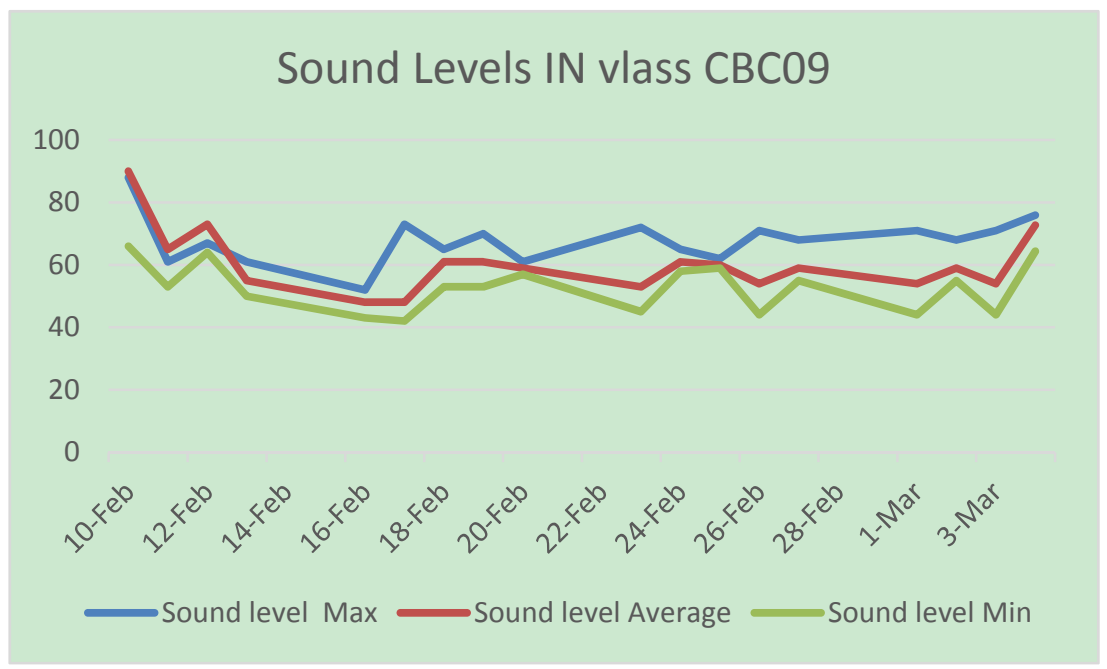

Figure 14. Max Sound Level $68 \mathrm{db}$. Average $60 \mathrm{~dB}$, Min $63 \mathrm{~dB}$ 


\section{Discussion}

The location is at the college of architecture engineering, architecture department. The measurements were done every day ate midday in the three classrooms $\mathrm{CBC} 01, \mathrm{CBC} 02$ and $\mathrm{CBC} 09$ this time is the peak time for these studio classes.

The results of sound level measured by sound meter (Figure 2) for class CBC01 is $55 \mathrm{~dB}$ which exceed the limit of sound for classroom announced by The Environmental Agency (EPA ). In addition, the result of sound level measured for studio class $\mathrm{CBC} 07$ is $58 \mathrm{~dB}$ which is also exceed the limit $35 \mathrm{~dB}$ announced by EPA. In addition to that the measurements of sound level of class $\mathrm{CBC} 09$ is $60 \mathrm{~dB}$, which is double $35 \mathrm{~dB}$ the limit announced by EPA.

The below table 2 shows the higher measurement of sound level is record for studio classroom CG09

Which is $68 \mathrm{~dB}$ at $12.00 \mathrm{pm}$ to $13.00 \mathrm{pm}$ which is the peak time for students at their break time and this studio classroom is facing the main hall. In addition, the lower measurement shows in Table 2 is measured for class CBC01 which is $60 \mathrm{~dB}$ which still far a way from the limit $35 \mathrm{~dB}$ by EPA.

The research results show the percentage of humidity and temperature are normal specially there is HVAC system in each class that the student could adjust the temperature in summer and winter.

Table 1. The sound level by United State Environmental Protection Agency (EPA)

\begin{tabular}{lc}
\hline The activity in the eternal spaces & The recommended Noise level $(\mathrm{dB})$ \\
\hline Seminar room & $35-30$ \\
Faculty members room & $40-35$ \\
Studio classes & $30-35$ \\
\hline
\end{tabular}

Table 2. Shows the average results of the temperature and humidity and the sound level, (EPA, 2017)

\begin{tabular}{lcccll}
\hline The measurements & CBC01 & CBC07 & CBC09 & The Average & Conclusion \\
\hline Internal Temperature & $21 \mathrm{C}^{\circ}$ & $21 \mathrm{C}^{\circ}$ & $21 \mathrm{C}^{\circ}$ & $21 \mathrm{C}^{\circ}$ & Within the limit \\
External Temperature & $18 \mathrm{C}^{\circ}$ & $20 \mathrm{C}^{\circ}$ & $20 \mathrm{C}^{\circ}$ & $19.3 \mathrm{C}^{\circ}$ & Within the limit \\
Max Humidity & $45 \%$ & $47 \%$ & $47 \%$ & $46.30 \%$ & Within the limit \\
Min Humidity & $15 \%$ & $12 \%$ & $12 \%$ & $13.00 \%$ & Within the limit \\
Max Sound Level & $62 \mathrm{~dB}$ & $62 \mathrm{~dB}$ & $68 \mathrm{~dB}$ & $64.00 \mathrm{~dB}$ & CBC09 Exceed the Limit of Sound $>35$ \\
Average Sound Level & $55 \mathrm{~dB}$ & $58 \mathrm{~dB}$ & $60 \mathrm{~dB}$ & $57.66 \mathrm{~dB}$ & Class Cbc01 the sound level within the limit $<35$ \\
Min Sound Level & $50 \mathrm{~dB}$ & $50 \mathrm{~dB}$ & $63 \mathrm{~dB}$ & $54.00 \mathrm{~dB}$ & Class Cbc01 the sound level within the limit $<35$ \\
\hline
\end{tabular}

\section{Recommendations}

-The research recommends using of insulation materials in the wall panel between the two classes

-In addition, the research recommends closing the opening high-level window between the two classes.

-As well as, the research recommends using of curtains for all the classes

-Change the doors into wooden door instead of glass materials.

-Using of solid walls portion's instead of lightweight partitions.

-The research recommends regular maintenance of Heating Ventilating Air Conditioning System.

-The researcher agreed to use control system in heating and cooling the class to control the temperature and the humidity in summer and winter. 
-The researcher suggested to the false ceiling in $1 \mathrm{~m}$. depth for the HVAC system to avoid the vibration.

-The research recommends using carpet on the floor to minimize the noise.

-The research recommends using the monitoring system and measuring the sound level in 3D machine lab and in the main hall.

\section{Acknowledgement}

The Researchers would like to Acknowledge Dar Al Uloom University, specially Deanship of Graduate students and research for funding this research. Dean of CADD, Research Committee and Prince Sultan University for giving this opportunity for DAU Students.

\section{References}

Abdelmoneim, H. (2019). Sustainable Eco Buildings Assessment Method to Evaluate Residential Buildings in Greater Khartoum, PhD research, Faculty of Architecture, UOFK, Sudan. Scholar Press, Germany.

Abdelmoneim, H. (2020a). Benchmarking case study, Applying Sustainable Eco-Building Assessment Method (SEBAM) in Greater Khartoum, comparing with global systems. Journal of Sustainable Development, 13(3). https://doi.org/10.5539/jsd.v13n3p33

Abdelmoneim, H. (2020b). Sustainable-Eco-Buildings Assessment Method (SEBAM) for The Evaluation of Residential Buildings in Hot dry Climate. Journal of Sustainable Development, 13(3).

Al Serf, M. (2019). Sustainable Houses in Saudi Arabia, Opportunities and Challenges, Universal Publisher.

Alwakil, Sh. (1989). The Climate and The Hot Region Building Architecture, Book Word, Abdelkhalig Tharuat Press, Egypt.

Araújo de, G. (2018). Relationship between thermal comfort indices an internal temperature of grazing lactating Holstein Gyr cows in western Amazonia. Amazonica, 48(3), 191-196. https://doi.org/10.1590/1809-4392201704301

ASHRAE. (2019). ANSI/ASHRAE Standard 62.2-2019, Ventilation and Acceptable Indoor Air Quality in Residential Buildings, USA.

Badran, R. (2005). The Architecture of Rasem Badran. Thames \& Hudson Press, UK.

Ermann, M. (2005). Architectural Acoustics Illustrated. WELLY Pres. Canada.

Fajal, K. (2002). Application on Environmental Design In Hot Desert Area (1st ed.). Cairo: Al Madina Library.

Fanger, P. O. (1970). Analysis and application in Environmental Engineering (1st ed.). USA/New York: Mac Grew Hill Company.

Hassan, S. (2000). The Principles of Environmental Urban Science (1st ed.). Khartoum: Sudan University.

Hassan, S. (2007). The Lighting and Acoustic in Architecture. Kink Saud Press, Saudi Arabia.

Jalil, A., Mjid, M., \& Safa, Kh. (2012). Study of Noise Level in the Building of Engineering college, civil department. The Iraqui Journal for Mechanical and Material Engineering, 12(4).

Jaramillo, A. (2012). Architectural Acoustics. Routledge Press. UK.

KAUST. (2013). Evaluation of The Green Industry in Saudi Arabia and the GCC Region: Technologies, Market, Assessment and Business Opportunities, Riyadh, KSA: King Abddulla University for Science and Technology.

Laaeddine, R., Wu, S., \& Del, E. (2019). A Review of Occupant's Energy Behavior Data Collection Methods and Techniques. Proceeding of ICITEE, Applied Science University, Bahrain.

Long, M. (2014). Architecture Acoustic. Book Aid Press, UK.

Mahmoud, S. (2019). Empirical Study in Image Denoising Using Total Variation Based On Color Space, Proceeding of ICITEE, Applied Science University, Bahrain.

Mcmullan, R. (2002). Environmental Science in Building (5th ed.). Martine's Press, UK.

Schiavon, S. (2010). Energy analysis of the personalized ventilation system in hot and humid climates. Energy and Buildings, (42), 699-707. https://doi.org/10.1016/j.enbuild.2009.11.009

Souq.com, S. (2020, Feb. 15 Sunday). Sound meter. Retrieved from https://saudi.souq.com/sa-en/sound-meter/s/?as=1 
Teresa, M. (2020). Outdoor Thermal and Acoustic Comfort in Autumn for Senior Citizens in Public Spaces in Newcastle Upon Tyne, United Kingdom. Journal of Scientific and Technical Research, 24(1). https://doi.org/10.26717/BJSTR.2020.24.004002

United State Environmental Agency (EPA). (2017). Sensible steps to Healtheir School Environment. P.10, USA.

Waziri, Y. (2010). Principle of Designing Natural Cooling Towers A Study Using Equations and Field Measurements. Riyadh, KSA, Conference on Technology and Sustainability in the Built Environment, King Saud University.

\section{Copyrights}

Copyright for this article is retained by the author(s), with first publication rights granted to the journal.

This is an open-access article distributed under the terms and conditions of the Creative Commons Attribution license (http://creativecommons.org/licenses/by/4.0/). 